\title{
Risk Factors for Gallstone Disease Requiring Surgery
}

\author{
CARLO LA VECCHIA***", EVA NEGRI*, BARBARA D'AVANZO*, SILVIA FRANCESCHI† AND PETER \\ BOYLE
}

La Vecchia C (Istituto di Ricerche Farmacologiche 'Mario Negri', Via Eritrea 62, 20157 Milano, Italy), Negri E, D'Avanzo B, Franceschi S and BoyleP. Risk factors for gallstone disease requiring surgery. International Journal of Epidemiology 1991, 20: 209-215.

Risk factors for cholelithiasis were investigated in a case-control study conducted in northern Italy on 195 incident cases of gallstone disease requiring surgery (119 females, 76 males) and 1122 controls in hospital for acute, nondigestive tract, non-neoplestic conditions. There was no consistent association with socio-demographic indicators, such as marital status, education and social class nor with smoking and coffee consumption. The relative risk of cholelithiasis decreased with increasing alcohol consumption: compared with non-drinkers, the odds ratio (OR) was 0.8 for one to three drinks per day and 0.5 for over three. A direct association was observed with measures of body weight: relative to leaner individuals, the multivariate ORs were 1.2, 2.1 and 2.4 for subsequent levels of body mass. These trends in risk were statistically significant, consistent in the two sexes, and not apparently modified by adjustment for major identified potential confounding factors. History of hepatitis and liver cirrhosis were reported more frequently by cases, but it is difficult to assess the role of recall bias on these risk factors. No association was found with diabetes, thyroid disease and several digestive tract disorders. For females, no consistent pattern of risk was observed up to four births, but women with five or more births had an OR of $2.9(95 \%$ confidence interval $(\mathrm{Cl})=1.1-7.3)$. The risk decreased with increasing age at first and last birth, both trends being statistically significant. Overweight and alcohol consumption were the most important risk and protective factors respectively for cholelithiasis requiring surgical intervention in this population.

Cholelithiasis is one of the most frequent causes of morbidity and surgery in industrialized countries. The reported frequency of the disease and the composition of the stones varies in different countries. In Okinawa, Japan, the overall prevalence was $3.2 \%$, ' while the prevalence plus ten-year cumulative incidence in the Framingham study was $8.2 \% .^{2}$ Prevalence of over $10 \%$ were found in other countries or in selected ethnic groups, such as Pima Indians. ${ }^{3-9}$ Some of these differences may be accounted for by different methods and accuracy of case ascertainment or by varying definition (i.e. clinical or surgical series as opposed to ultrasound or autopsy-based studies), but it is unlikely that this can explain all of the variation which is observed between different populations. ${ }^{3-16}$

Knowledge of the causes of gallstone disease is poor.

\footnotetext{
'Istituto di Ricerche Farmacologiche 'Mario Negri', Via Eritrea 62, 20157 Milano, Italy.

**Institut universitaire de médecine sociale et préventive, Bugnon 17, 1005 Lausanne Switzerland.

tCentro di Riferimento Oncologico, 33081 Aviano (PN), Italy

fUnit of Analytical Epidemiology, The International Agency for Research on Cancer, 150 Cours Albert Thomas, 69372 Lyon, France.
}

The clinical observation that the typical patient with gallstones is 'fat, fertile, female and forty' has found only partial support in formal epidemiological studies. While, in fact, in all populations higher rates were observed in females, the incidence of the disease appears to increase steadily with age, rather than levelling off in younger middle age, both in low (Japan) ${ }^{\prime}$ and high (USA) ${ }^{2}$ incidence areas. Whereas obesity is a well established risk factor in all reported investigations, ${ }^{2,17-22}$ the relation with parity is neither strong nor consistent in various studies. ${ }^{2,17,22,23}$

Likewise, no consistent association has been observed with serum cholesterol or various lipoproteins, diabetes and hyperinsulinaemia, ${ }^{2,1724}$ and there are uncertainties regarding the relation with oral contraceptives ${ }^{17.23}$ and exogenous oestrogens. ${ }^{26.27}$ Alcohol seems to reduce the risk of gallstone disease, ${ }^{2,18,21,22}$ but no consistent association has been found with tobacco, coffee and other components of the diet ${ }^{2.17 .20}$ except, possibly, total energy intake. ${ }^{21}$

To further clarify the risk factors for gallstone disease requiring surgery, a formal epidemiological study has been conducted within the framework of a 
hospital-based case-control surveillance of the greater Milan area in northern Italy. In a European context, this is a high prevalence ${ }^{28.29}$ and mortality ${ }^{30}$ area.

\section{SUBJECTS AND METHODS}

The data were derived from an ongoing series of casecontrol studies of several digestive tract disorders, based on a network of teaching and general hospitals from the greater Milan area. ${ }^{31}$ Recruitment of cases of gallstone disease started in June 1987, and the present report is based on data collected up to June 1989.

The general design of this study has been described previously. ${ }^{31}$ Trained interviewers identified and questioned patients admitted to university and general hospitals in the area under surveillance for gallstone disease requiring surgery and for a wide spectrum of other conditions. All interviews were conducted in hospital. On average, less than $3 \%$ of eligible subjects (both cases and controls) refused to be interviewed.

\section{Cases}

The cases studied were subjects below the age of 75 with a discharge diagnosis of 'cholelithiasis' or 'cholecystitis', whose original diagnosis did not date back more than one year before admission ('incident cases'), and who had undergone cholecystectomy during the monitored admission. They were admitted to several University departments (chiefly of surgery) and to the Ospedale Maggiore, which includes the four largest teaching and general hospitals in Milan. Altogether 195 patients ( 76 males, 119 females) were interviewed. The age range was between 23 and 74 years and the median age was 55 years.

\section{Controls}

Patients admitted for a wide spectrum of acute conditions to the same network of hospitals were eligible as controls. None of these patients had digestive tract disorders, malignant tumours, or any conditions related to alcohol and tobacco intake or which might have resulted in long-term modification of diet. Further, none of the controls had history of gallbladder disease. A total of 1122 controls (685 males, 437 females) were considered in the present analysis. Of these, $39 \%$ were admitted for traumatic conditions (mostly fractures and sprains), $20 \%$ had non-traumatic orthopaedic disorders (mostly low-back pain and disc disorders), $22 \%$ were admitted for acute surgical conditions (including plastic surgery), and $19 \%$ had other illnesses, such as ear, nose and throat, skin or dental disorders. The age range of the comparison group was 21 to 74 years, median age 58 years. The distribution of cases and controls according to age and sex is given in Table 1.
The catchment area of cases and controls was comparable: overall, $92 \%$ of the cases and $86 \%$ of the controls were resident in the same region, Lombardy. A large proportion came from the highly industrialized area of greater Milan, which includes about $50 \%$ of the population of the whole region.

A structured questionnaire was used to obtain information on socio-demographic factors and general characteristics and habits, including smoking, alcohol, coffee and other methylxanthine-containing beverage consumption, frequency of consumption per week of 29 selected indicator foods, related personal and family medical history, history of use of selected drugs, and (for females only) reproductive and contraceptive history.

\section{Data Analysis and Control of Confounding}

Relative risks were approximated by the odds ratio (OR) of gallstone disease, together with their $95 \%$ confidence intervals (CI) and were first derived from data stratified for sex and age in decades by the usual Mantel-Haenzel procedure. ${ }^{32}$ For multiple levels of exposure, significance was assessed by Mantel's extension test. ${ }^{33}$ Secondly, to account simultaneously for several potential confounders, multiple logistic regression was used, with maximum likelihood fitting. ${ }^{34.35}$ All the regression equations included terms for age, sex, area of residence, smoking, coffee and alcohol consumption, history of liver disease and body mass index (plus, whenever indicated, for reproductive variables).

TABLE 1 Distribution of 195 cases of cholelithiasis and 1122 controls according to sex, age group and selected socio-demographic factors. Milan, Italy 1987-1989

\begin{tabular}{lccccc}
\hline & \multicolumn{3}{c}{ Males } & \multicolumn{3}{c}{ Females } \\
\cline { 5 - 6 } \cline { 5 - 6 } & Cholelithiasis & Controls & Cholelithiasis & Controls \\
\hline Age (years) & & & & & \\
$<45$ & 18 & 137 & & 35 & 64 \\
$45-54$ & 19 & 193 & & 20 & 101 \\
$55-64$ & 26 & 204 & & 44 & 143 \\
$65-74$ & 13 & 151 & 20 & 129 \\
Marital status & & & & \\
Never married & 6 & 69 & 10 & 52 \\
Married & 70 & 616 & 109 & 385 \\
Education (years) & & & & \\
$<7$ & 29 & 335 & 63 & 236 \\
$7-11$ & 23 & 191 & 34 & 118 \\
$>12$ & 24 & 158 & 19 & 83 \\
Social classt & & & & \\
I or II & 10 & 55 & 7 & 44 \\
III & 41 & 229 & 43 & 143 \\
IV or V & 22 & 333 & 59 & 177 \\
Undefined & 3 & 68 & 10 & 73 \\
\hline
\end{tabular}

"In some cases, the sum of strata does not add up to the total because of missing values.

+Based on the head of the household's occupation. 
Dose gradients in the logistic models were based on chi-square values for trend, computed as the difference between the deviance of the models without and with the variable of interest.

\section{RESULTS}

Table 1 gives the distribution of cases of cholelithiasis and the comparison group according to sex, age, marital status and socioeconomic indicators. Cases were slightly younger, but there was no difference in relation to marital status. Some inconsistency in socioeconomic indicators was noted since male cases tended to be more educated and of higher social class, while the reverse was observed for females.

For sociodemographic indicators (Table 2) no consistent association was observed between gallstone disease and smoking or coffee consumption: the relative risk was 1.1 for both ex-smokers and current smokers (and no relation was observed with quantity smoked as well, data not shown), and the risk estimates were around unity for all subsequent levels of coffee consumption.

In relation to alcohol consumption (Table 3), a significant inverse relationship emerged with the risk of cholelithiasis: compared with non-drinkers, the sexand age-adjusted risk estimates were 0.8 for one to three drinks per day, and 0.5 for over three, and the trend in risk with dose was highly significant. This inverse association was consistent in the two sexes and virtually unmodified after allowing for a number of covariates through multiple logistic regression.
Gallstone disease was directly and significantly related to overweight (Table 4). Compared with leaner subjects, (whose body mass index, expressed in $\mathrm{kg} \mathrm{m}^{-2}$ was below 20), the relative risks were $1.1,1.4$ and 1.7 for subsequent levels of body mass. This association, again, was of similar magnitude in males and females and persisted after allowing for major identified covariates. Indeed, the multivariate risks were higher than the univariate ones $(1.1,2.1$, and 2.4 for subsequent levels respectively).

Table 5 considers history of hepatitis and selected liver diseases. Of the cases $8 \%$ as opposed to $3.6 \%$ of the controls reported a history of hepatitis, giving a relative risk of $2.6(95 \% \mathrm{CI}=1.5-4.2)$. Liver cirrhosis was only reported by three cases and five controls (relative risk 4.7) of borderline statistical significance. No significant difference emerged for diabetes $(4.4 \%$ of the cases versus $4.1 \%$ of the controls), thyroid disease, gastro-duodenal ulcer or any other gastrointestinal disease, except appendicectomy $(47 \%$ of cases versus $35 \%$ of the controls, OR $=1.4,95 \%$ $\mathrm{CI}=1.0-2.0$ ).

Reproductive variables (for females only) are considered in Table 6 . In relation to parity, no consistent pattern of risk was observed up to four births, with relative risks of $1.0,1.5$ and 0.7 for women with one, two and three or four births compared to nulliparous ones. Only women with five or more births had a significantly elevated $\mathrm{OR}$ of $3.1(95 \% \mathrm{CI}=1.3-7.3)$. The risk decreased with increasing age at first and last birth:

TABLE 2 Distribution of 195 cases of cholelithiasis and 1122 controls according to smoking habits and coffee consumption. Milan, Italy, $1987-89$

\begin{tabular}{|c|c|c|c|c|}
\hline & \multirow[b]{2}{*}{ Cholelithiasis } & \multirow[b]{2}{*}{ Controls } & \multicolumn{2}{|c|}{ Relative Risk Estimates ( $95 \% \mathrm{CI}$ ) } \\
\hline & & & $\mathbf{M}-\mathrm{H}^{*}$ & MLR** \\
\hline \multicolumn{5}{|l|}{ Smoking habits } \\
\hline Never smokers & 97 & 490 & $1 \dagger$ & $1 \dagger$ \\
\hline Ex smokers & 31 & 424 & $\begin{array}{c}1.1 \\
(0.7-1.9)\end{array}$ & $\begin{array}{c}1.4 \\
(0.8-2.3)\end{array}$ \\
\hline Current smokers & 67 & 208 & $\begin{array}{c}1.1 \\
(0.8-1.6)\end{array}$ & $\begin{array}{c}1.1 \\
(0.8-1.7)\end{array}$ \\
\hline \multicolumn{5}{|c|}{ Coffee consumption (cups per day) } \\
\hline 0 & 28 & 173 & $1+$ & $1+$ \\
\hline 1 & 46 & 244 & $\begin{array}{c}1.1 \\
(0.7-1.8)\end{array}$ & $\begin{array}{c}1.1 \\
(0.7-1.9)\end{array}$ \\
\hline 2 & 48 & 317 & $\begin{array}{c}0.9 \\
(0.5-1.5)\end{array}$ & $\begin{array}{c}0.9 \\
(0.5-1.5)\end{array}$ \\
\hline 3 & 38 & 205 & $\begin{array}{c}1.1 \\
(0.6-1.9)\end{array}$ & $\begin{array}{c}1.0 \\
(0.6-1.7)\end{array}$ \\
\hline$\geq 4$ & 35 & 183 & $\begin{array}{c}1.3 \\
(0.7-2.3)\end{array}$ & $\begin{array}{c}0.9 \\
(0.5-1.6)\end{array}$ \\
\hline$x_{1}^{2}($ trend $)$ & & & $\begin{array}{l}0.18 \\
(n . s)\end{array}$ & $\begin{array}{c}0.40 \\
\text { (n.s.) }\end{array}$ \\
\hline
\end{tabular}

"Mantel-Haenzel estimates adjusted for age and sex.

* Estimates from multiple logistic regression equations induding terms for age, sex, area of residence, smoking, coffee and alcohol consumption, history of liver disease and body mass index.

tReference category. 
TABLE 3 Distribution of 195 cases of cholelithiasis and 1122 controls according to alcohol consumption. Milan, Italy, 1987-89

\begin{tabular}{|c|c|c|c|c|}
\hline & \multirow[b]{2}{*}{ Cholelithiasis } & \multirow[b]{2}{*}{ Controls } & \multicolumn{2}{|c|}{ Relative Risk Estimates ( $95 \% \mathrm{CI}$ ) } \\
\hline & & & $\mathbf{M}-\mathrm{H}^{*}$ & MLR** \\
\hline \multicolumn{5}{|c|}{$\begin{array}{l}\text { Total alcohol beverage consumption } \\
\text { (drinks per day) }\end{array}$} \\
\hline 0 & 75 & 286 & $1 \dagger$ & $1 \dagger$ \\
\hline $1-3$ & 90 & 464 & $\begin{array}{c}0.8 \\
(0.6-1.2)\end{array}$ & $\begin{array}{c}0.8 \\
(0.6-1.3)\end{array}$ \\
\hline$>3$ & 30 & 372 & $\begin{array}{c}0.5 \\
(0.3-0.9)\end{array}$ & $\begin{array}{c}0.5 \\
(0.3-0.8)\end{array}$ \\
\hline$x_{1}^{2}($ trend $)$ & & & $\begin{array}{c}11.08 \\
(p<0.001)\end{array}$ & $\begin{array}{c}7.04 \\
(p=0.008)\end{array}$ \\
\hline
\end{tabular}

- Mantel-Haenzel estimates adjusted for age and sex.

** Estimates from multiple logistic regression equations including terms for age, sex, area of residence, smoking, coffee and alcohol consumption, history of liver disease and body mass index.

tReference category.

compared with women who first gave birth at age 25 or less, the OR was 0.7 for 25 to 29 , and 0.5 for 30 or over. In relation to age at last birth, compared with 30 or less, the point estimates were 0.7 and 0.6 for 30 to 34 and 35 or over respectively. Both univariate trends in risk were significant, and the associations with reproductive variables were not materially affected by adjustment for other covariates. When both parity and age at first or last birth were included in the same logistic model, the effects of various factors appeared independent, since the risk estimates were consistently above unity for women with five or more births and below unity for late age at first or last birth.

\section{DISCUSSION}

This case-control study of cholelithiasis requiring surgery provided further information regarding some important environmental determinants of the disease, in particular confirming that the occurrence of gall- stones is related to overweight and gross multiparity (five or more births, although there was no association up to four births). ${ }^{17-20,23}$ Further, it provided quantitative information on the protection given by moderate alcohol consumption in a population characterized by frequent intake of alcoholic beverages. ${ }^{36}$ Of interest, moreover, were the positive associations with history of hepatitis (and liver cirrhosis), although numbers were small and the possibility of differential recall by cases and controls could be substantial. The lack of, or inconsistent, associations with measures of social class, smoking and coffee should be noted as well.

Some of these findings were already known, particularly the relationship between cholelithiasis and obesity, and this study simply offers further quantitative information. More important, in our view, is the contribution made towards defining the protective effect of alcohol intake, previously suggested by the Framingham cohort study, ${ }^{2}$ the American Nurses' Health

TABLE 4 Distribution of 195 cases of cholelithiasis and 1122 controls according to body mass index. Milan, Italy, 1987-89

\begin{tabular}{|c|c|c|c|c|}
\hline & \multirow[b]{2}{*}{ Cholelithiasis } & \multirow[b]{2}{*}{ Controls } & \multicolumn{2}{|c|}{ Relative Risk Estimates $(95 \% \mathrm{CI})$} \\
\hline & & & $\mathbf{M}-\mathbf{H}^{*}$ & MLR** \\
\hline \multicolumn{5}{|c|}{ Body mass index $\left(\mathrm{kg} / \mathrm{m}^{2}\right)$} \\
\hline$<20$ & 19 & 104 & $1+$ & $1 \dagger$ \\
\hline $20-24$ & 82 & 553 & $\begin{array}{c}1.1 \\
(0.6-1.9)\end{array}$ & $\begin{array}{c}1.2 \\
(0.7-2.2)\end{array}$ \\
\hline $25-29$ & 71 & 370 & $\begin{array}{c}1.4 \\
(0.8-2.5)\end{array}$ & $\begin{array}{c}2.1 \\
(1.1-3.8)\end{array}$ \\
\hline$\geq 30$ & 23 & 90 & $\begin{array}{c}1.7 \\
(0.9-3.4)\end{array}$ & $\begin{array}{c}2.4 \\
(1.1-4.9)\end{array}$ \\
\hline $\begin{array}{l}\text { Unknown } \\
x_{1}^{2} \text { (trend) }\end{array}$ & - & 5 & $\begin{array}{c}6.29 \\
(p=0.01)\end{array}$ & $\begin{array}{c}11.20 \\
(p<0.001)\end{array}$ \\
\hline
\end{tabular}

* Mantel-Haenzel extimates adjusted for age and sex.

"Estimates from multiple logistic regression equations including terms for age, sex, area of residence, smoking, coffee and alcohol consumption, history of liver disease and body mass index.

tReference category. 
TABLE 5 Distribution of 195 cases of cholelithiasis and 1122 controls according to history of liver disease. Milan, Italy, $1987-89$

\begin{tabular}{|c|c|c|c|c|}
\hline & & & Relative Risk F & ates $(95 \% \mathrm{Cl})$ \\
\hline & Cholelithiasis & Controls & $\mathbf{M}-\mathbf{H}^{*}$ & MLR** \\
\hline Hepati & & & & \\
\hline No & 179 & 1082 & $1 \dagger$ & $1 \dagger$ \\
\hline Yes & 16 & 40 & $\begin{array}{c}2.6 \\
(1.5-4.7)\end{array}$ & $\begin{array}{c}2.7 \\
(1.4-5.1)\end{array}$ \\
\hline Cirrhos & & & & \\
\hline No & 192 & 1117 & $1 \dagger$ & $1 \dagger$ \\
\hline Yes & 3 & 5 & $\begin{array}{c}4.7 \\
(1.3-16.7)\end{array}$ & $\begin{array}{c}3.7 \\
(0.8-16.8)\end{array}$ \\
\hline
\end{tabular}

- Mantel-Haenzel estimates adjusted for age and sex.

**Estimates from multiple logistic regression equations including terms for age, sex, area of residence, smoking, coffee and alcohol consumption, history of liver disease and body mass index.

†Reference category.

study, ${ }^{21}$ case-control studies for Australia ${ }^{20}$ and on Hispanic Americans, ${ }^{22}$ as well as by a preliminary report of this same study. ${ }^{\mathfrak{h}}$ Further, this study helped clarify other issues, such as those related to reproductive factors.

The small association with parity, restricted to women with five or more births, and the inverse relation with age at first or last birth, are consistent with the results of a case-control study conducted in Australia. ${ }^{23}$ In the Oxford Family Planning Cohort Study (restricted to women below the age of 50, and chiefly in their thirties and forties) a stronger association with parity was observed, and the relation with age at first birth was direct rather than inverse. ${ }^{17}$ It is probable that most of these apparent discrepancies are due to the different age distribution in the various studies. Although some role of chance or bias cannot be ruled out, it is possible that pregnancy, or oral contraceptive usage $\mathrm{e}^{22.25}$ have a chiefly short-term impact on the risk of gallbladder diseases. Along these lines, an excess of multiparous women in the younger age groups only was also observed in a study on Pima Indians. ${ }^{4}$

TABLE 6 Distribution of 119 female cases of choletithiasis and 437 controls according to reproductive history. Milan, Italy, 1987-89

\begin{tabular}{|c|c|c|c|c|c|}
\hline & \multirow[b]{2}{*}{ Cholelithiasis } & \multirow[b]{2}{*}{ Controls } & \multicolumn{3}{|c|}{ Relative Risk Estimates $(95 \% \mathrm{CI})$} \\
\hline & & & $\mathrm{M}-\mathrm{H}^{*}$ & MLR** & MLR§ \\
\hline \multicolumn{6}{|c|}{ Number of births } \\
\hline 0 & 21 & 92 & $1 \dagger$ & $1 \dagger$ & - \\
\hline 1 & 27 & 113 & $\begin{array}{c}1.1 \\
(0.6-2.1)\end{array}$ & $\begin{array}{c}1.0 \\
(0.5-2.1)\end{array}$ & $1 \dagger$ \\
\hline 2 & 47 & 136 & $\begin{array}{c}1.7 \\
(0.9-3.2)\end{array}$ & $\begin{array}{c}1.8 \\
(0.9-3.4)\end{array}$ & $\begin{array}{c}1.6 \\
(0.9-2.9)\end{array}$ \\
\hline $3-4$ & 11 & 72 & $\begin{array}{c}0.8 \\
(0.3-1.8)\end{array}$ & $\begin{array}{c}0.7 \\
(0.3-1.7)\end{array}$ & $\begin{array}{c}0.6 \\
(0.2-1.3)\end{array}$ \\
\hline$\geq 5$ & 13 & 24 & $\begin{array}{c}3.1 \\
(1.3-7.3)\end{array}$ & $\begin{array}{c}2.9 \\
(1.1-7.3)\end{array}$ & $\begin{array}{c}2.3 \\
(0.9-5.7)\end{array}$ \\
\hline$x_{1}^{2}($ trend $)$ & & & $\begin{array}{c}3.05 \\
(p=0.08)\end{array}$ & $\begin{array}{c}2.14 \\
(p=0.14)\end{array}$ & $\begin{array}{r}0.23 \\
\text { (n.s.) }\end{array}$ \\
\hline \multicolumn{6}{|c|}{ Age at first birth (years) } \\
\hline$<25$ & 55 & 154 & $1 \dagger$ & $1 \dagger$ & $1 \dagger$ \\
\hline $25-29$ & 33 & 121 & $\begin{array}{c}0.7 \\
(0.4-1.2)\end{array}$ & $\begin{array}{c}0.7 \\
(0.4-1.2)\end{array}$ & $\begin{array}{c}0.8 \\
(0.4-1.4)\end{array}$ \\
\hline$\geq 30$ & 10 & 70 & $\begin{array}{c}0.5 \\
(0.2-0.9)\end{array}$ & $\begin{array}{c}0.5 \\
(0.2-1.0)\end{array}$ & $\begin{array}{c}0.5 \\
(0.2-1.1)\end{array}$ \\
\hline$x_{1}^{2}($ trend $)$ & & & $\begin{array}{c}5.87 \\
(p=0.02)\end{array}$ & $\begin{array}{c}4.32 \\
(p=0.04)\end{array}$ & $\begin{array}{c}3.27 \\
(p=0.07)\end{array}$ \\
\hline \multicolumn{6}{|c|}{ Age at last birth (years) } \\
\hline$<30$ & 57 & 149 & $1 \dagger$ & $1 \dagger$ & $1 \dagger$ \\
\hline $30-34$ & 26 & 113 & $\begin{array}{c}0.7 \\
(0.4-1.2)\end{array}$ & $\begin{array}{c}0.7 \\
(0.4-1.2)\end{array}$ & $\begin{array}{c}0.5 \\
(0.3-1.0)\end{array}$ \\
\hline$\geqslant 35$ & 15 & 83 & $\begin{array}{c}0.6 \\
(0.3-1.1)\end{array}$ & $\begin{array}{c}0.6 \\
(0.3-1.1)\end{array}$ & $\begin{array}{c}0.3 \\
(0.1-0.7)\end{array}$ \\
\hline$x_{1}^{2}$ (trend) & & & $\begin{array}{c}3.87 \\
(p=0.05)\end{array}$ & $\begin{array}{c}3.26 \\
(p=0.07)\end{array}$ & $\begin{array}{c}8.42 \\
(p=0.004)\end{array}$ \\
\hline
\end{tabular}

- Mantel-Haenzel estimates adjusted for age and sex.

* Estimates from multiple logistic regression equations including terms for age, sex, area of residence, smoking, coffee and alcohol consumption, history of liver disease and body mass index.

\$Estimates from multiple logistic regression equations including terms for the above listed non-reproductive variables, plus parity and age at first or last birth (excluding nulliparae).

tReference category. 
Case ascertainment was restricted to subjects requiring hospital admission and surgery for gallstones. This might be viewed as a restrictive and limited criterion for selection of the whole population with gallbladder disease, since a large proportion of subjects with no or mild symptoms can be detected only through ultrasound or other types of screening and a proportion of symptomatic patients is treated with non-surgical therapies. In particular, the indications for surgery are extremely varied from country to country and from surgeon to surgeon and this is reflected in gross differences in cholecystectomy rates in various areas. ${ }^{38-42}$ Thus, the risk estimates derived from this study could strictly only be applied to the present population, and quantitative differences in these estimates are possible using different definition and selection criteria (although qualitative differences in the direction of the associations are unlikely). Furthermore, our study population of gallbladder disease requiring surgery constitutes a natural selection from a public health (and clinical) viewpoint, and, in this sense, the inferences drawn are directly applicable to the clinically most relevant fraction of the disease.

Other strengths and limitations of this study are common to most hospital-based case-control studies. ${ }^{32}$ The possible impact of selection bias is reduced by the practically total participation rate and the comparable catchment areas of cases and controls. Information bias has almost certainly influenced variables like history of liver disease, but it is unlikely to have materially affected other factors, like body weight, reproductive history and also reported alcohol intake, since moderate alcoholic beverage consumption, particularly during meals, is socially accepted in Italy for both males and females. ${ }^{36}$ In relation to confounding, most of the associations observed remained virtually unchanged after allowing for a number of identified potential distorting factors.

In biological terms, an explanation for the absence of an association with coffee and the inverse association with alchohol would probably be sought in the complex effects of these beverages on lipoprotein serum levels and composition. Alcohol reduces bile cholesterol secretion and increases HDL-cholesterol, ${ }^{43}$ which is probably the basis of the possible protection of moderate alcohol consumption on the risk of ischaemic heart disease. ${ }^{-16}$ Coffee consumption reduces bile acid and neutral sterol secretion, ${ }^{47}$ but this does not appear to have an important impact on the risk of cholelithiasis.

In public health terms, the major preventive implication of this study lies in confirmation of the role of overweight and obesity, since modification of this risk factor is, at least in principle, possible and beneficial not only for such a frequent disease as cholelithiasis, but also for gallbladder cancer risk ${ }^{48}$ and a large spectrum of $\sim$ ther conditions. ${ }^{49.50}$

\section{ACKNOWLEDGEMENTS}

This work was conducted within the framework of the CNR (Italian National Research Council) Applied Projects 'Oncology' (Contract No. 87.01544.44) and 'Risk Factors for Disease'. The contribution of the Italian Association for Cancer Research and the Italian League Against Tumours, Milan, Italy are gratefully acknowledged. We wish to thank Mrs Janin for editorial assistance.

\section{REFERENCES}

' Nomura H, Kashiwagi S, Hayashi J, Kajiyama W, lkematsu H, Noguchi A, et al. Prevalence of gallstone disease in a general population of Okinawa, Japan. Am J Epidemiol 1988; 128: 598-605.

${ }^{2}$ Friedman G D, Kannel W B, Dawber T R. The epidemiology of gallbladder disease: observations in the Framingham study. $J$ Chron Dis 1966; 19: 273-92.

${ }^{3}$ Comess L J, Bennett P H, Burch T A. Clinical gallbladder disease in Pima Indians. N Engl J Med 1967; 277: 894-8.

4 Sampliner R E, Bennett P H, Comess L J, et al. Gallbladder disease in Pima Indians. N Engl J Med 1970; 283: 1358-64.

'Bainton D, Davies G T, Evans K T, Gravelle I H. Gallbladder disease: prevalence in a South Wales industrial town. $N$ Engl J Med 1976; 294: 1147-9.

${ }^{6}$ Williams C N, Johnston J L, Weldon K L M. Prevalence of gallstones and gallbladder disease in Canadian Micmac Indian women. Can Med Ass J 1977; 117: 758-60.

${ }^{7}$ Diehl A K, Stern M P, Ostrover V S, Friedman P C. Prevalence of clinical gallbladder disease in Mexican-American, Anglo and Black women. South Med J 1980; 73: 438-43

'Malhotra S L. Epidemiological study of cholelithiasis among railroad workers in India with special reference to causation. Gut 1968; 9: $290-5$.

'Torvik A, Hoivik B. Gallstones in an autopsy series. Acta Chir Scand 1960; 120: 168-74.

${ }^{10}$ Zahor S, Stemby N H, Kagan A, et al. Frequency of cholelithiasis in Prague and Malmo: an autopsy study. Scand J Gastroenterol 1974; 9: 3-7.

"Bateson M, Bouchier I D. Prevalence of gallstones in Dundee: a necropsy study. $\mathrm{Br}$ Med $J$ 1975; 4: 427-30.

${ }^{12}$ Lindstrom C G. Frequency of gallstone disease in a well-defined Swedish population: a prospective necropsy study in Malmo. Scand J Gastroenterol 1977; 12: 341-6.

${ }^{13}$ Barker D I P, Gardner M J, Power C, et al. Prevalence of gallstones at necropsy in nine British towns: a collaborative study. $\mathrm{Br}$ Med J 1979; 2: 1389-92.

${ }^{14}$ Domellof L, Lowenfels A B, Sipponen P. Prevalence of gallstones in Finland: an autopsy study in the Helsinki area. Scand $J$ Gastroenteral 1984; 19: 761-4.

${ }^{13}$ Sichieri R, Everhart J E, Roth H P. Low incidence of hospitalization with gallbladder disease among blacks in the United States. Am J Epidmiol 1990; 131: 826-35.

${ }^{16}$ Brett M, Barker D J P. The world distribution of gallstones. Int J Epidemiol 1976; 5: 535-41.

"Layde P M, Vessey M P, Yeates D. Risk factors for gallbladder disease: a cohort study of young women attending family planning clinics. J Epidemiol Community Health 1982; 36: 274-8. 
${ }^{1}$ Haffner S M, Diehl A K, Stern M P, Hazuda H P. Central adiposity and gallbladder disease in Mexican Americans. Am J Epidemiol 1989; 129: 587-95.

"Diehl A K, Haffner S M, Hazuda H P, Stern M P. Coronary risk factors and clinical gallbladder disease: an approach to the prevention of gallstones. Am J Public Health 1987; 77: 841-5.

${ }^{20}$ Scragg R K R, McMichael A J, Baghurst P A. Diet, alcohol and relative weight in gallstone disease: a case-control study. Br Med J 1984; 288: 1113-9.

${ }^{21}$ Macture K M, Hayes K C, Colditz G A, Stampfer M J, Speizer F E, Willett W C. Weight, diet and the risk of symptomatic gallstones in middle-aged women. N Engl J Med 1989; 321: 563-9.

${ }^{2}$ Maurer K R, Everhart J E, Knowler W C, Shawker T H, Roth H P. Risk factors for gallstone disease in the Hispanic populations of the United States. Am J Epidemiol 1990; 131: 836-44.

${ }^{23}$ Scragg R K R, McMichael A J, Seamark R F. Oral contraceptives, pregnancy, and endogenous oestrogen in gallstone disease- $a$ case-control study. Br Med J 1984; 288: 1795-9.

${ }^{24}$ Scragg R K R, Calvert D G, Oliver J R. Plasma lipids and insulin in gallstone disease: a case-control study. $\mathrm{Br}$ Med J 1984; 289: 521-5.

${ }^{3}$ Royal College of General Practitioners' Oral Contraception Study. Oral contraceptives and gallbladder disease. Lancet 1982; 2: 957-9.

${ }^{20}$ Kakar F, Weiss N S, Strite S A. Non-contraceptive estrogen use and the risk of gallstone disease in women. Am J Public Health 1988; 78: $564-6$.

${ }^{77}$ Boston Collaborative Drug Surveillance Program, Boston University Medical Centre. Surgically confirmed gallbladder disease, venous thromboembolism, and breast tumors in relation to post-menopausal estrogen therapy. $N$ Engl J Med 1974; 290: 15-19.

2 Barbara L, Sama C, Labate A M M, et al. A population study on the prevalence of gallstone disease; the Sirmione study. Hepatology 1987; 7: 913-7.

GREPCO. Prevalence of gallstone disease in an Italian adult female population. Am J Epidemiol 1984; 119 : 796-805.

${ }^{3}$ Holland W W, (ed.) European Community Allas of Avoidable death. Oxford, Oxford University Press, 1988.

${ }^{31}$ La Vecchia C, Negri E, Decarli A, et al. A case-control study of diet and colorectal cancer in northern Italy. Int J Cancer 1988; 11 : $492-8$.

${ }^{2}$ Mantel N, Haenszel W. Statistical aspects of the analysis of data from retrospective studies of disease. $J N C l 1959 ; 22: 719-48$.

$\checkmark$ Mantel N. Chi-square tests with one degree of freedom: extension of the Mantel-Haenzel procedure. J Amer Stat Ass 1963; 58: $690-700$.
${ }^{34}$ Breslow N E, Day N E. Statistical methods in cancer research. IARC Sci Publication 32, Vol. 1. The analysis of case-control studies. Lyon, IARC, 1980.

${ }^{\square}$ Baker R J, Nelder J A. The GLIM system. Release 3. Numerical Algorithms Group, Oxford, 1978.

* La Vecchia C, Pagano R, Negri E, Decarli A. Determinants of alcohol consumption in Italy. Int J Epidemiol 1987; 16: 295-6.

${ }^{77}$ La Vecchia C, Negri E, D'Avanzo B, Boyle P. The risk of gallstones in middle-aged women. $N$ Engl J Med 1990; 322: 473.

"Bateson M C. (ed.) Gallstone disease and its maragement. Lancaster: MTP, 1986.

"Lund J. Surgical indications in cholelithiasis: prophylactic cholecystectomy elucidated on the basis of long-term follow up on 526 non-operated cases. Ann Surg 1960; 151: 153-62.

" Magee R B, MacDuffee R C. One thousand consecutive cholecystectomies. Arch Surg 1968; 96: 858-62.

${ }^{4}$ Holland C, Heaton K W. Increasing frequency of gallbladder operations in the Bristol area. Br Med J 1972; 3: 672-5.

"Kakar F, Weiss N S, Strite S A. Thiazide use and the risk of cholecystectomy in women. Am J Epidemiol 1986; 124: 248-53.

${ }^{43}$ Thornton J, Symes C, Heaton K. Moderate alcohol intake reduces bile cholesterol saturation and raises HDL cholesterol. Lancet 1983; 2: 819-22.

" Dai W S, Laporte R E, Hom D L, Kuller L H, D'Antonio J A, Gutai $\mathrm{J} P$, et al. Alcohol consumption and high density lipoprotein cholesterol concentration among alcoholics. Am J Epidemiol 1985; 122: 620-7.

${ }^{*}$ Stampfer M J, Colditz G A, Willett W C, Speizer F E, Hennekens C $H$. A prospective study of moderate alcohol consumption and the risk of coronary disease and stroke in women. $N$ Engl J Med 1988; 319: 267-73.

${ }^{4}$ Marmot M G. Akchol and coronary heart disease. Int $J$ Epidemiol 1984; 13: 160-7.

7 Jacobsen B K, Thelle D S. Coffee, cholesterol and colon cancer: is there a link? Br Med J 1987; 294: 4-5.

${ }^{43}$ Lew E A, Garfinkel L. Variations in mortality by weight among 750000 men and women. $J$ Chron $D$ is $1979 ; 32: 563-76$.

"Garfinkel L, Stellman S D. Mortality by relative weight and exercise. Cancer 1988; 62: 1844-50.

${ }^{*}$ Negri E, Pagano R, Decarli A, La Vecchia C. Body weight and the prevalence of chronic diseases. I Epidemiol Comm Health 1988; 42: 24-9

(Revised version received July 1990) 